\title{
Inmovilización de enzimas
}

\author{
Hugo Aviles Cabral ${ }^{\mathrm{a}}$, Javier Jesús Dorantes Adame ${ }^{\mathrm{a}}$ Guadalupe Calva Neria ${ }^{\mathrm{a}}$, Carlos Alexander Lucho Constantino ${ }^{\mathrm{b}}$, Rosa \\ Icela Beltrán Hernández ${ }^{\mathrm{b} *}$ \\ ${ }^{\mathrm{a}, \mathrm{b}}$ Universidad Autónoma del Estado de Hidalgo, Área Académica de Química. Carretera Pachuca-Tulancingo km 4.5, Mineral de la Reforma, Hidalgo, C.P. 42184, \\ México
}

\section{Resumen}

Existe una amplia diversidad de métodos para inmovilizar enzimas y para seleccionar alguno de ellos debe considerarse la enzima en cuestión, así como las características del proceso y los recursos e infraestructura disponibles. En este trabajo se ensayó el método de atrapamiento en gel de alginato para inmovilizar la pectinasa, una enzima de gran utilidad en la industria de alimentos.

Palabras Clave: pectinasa, alginato, gelificación, inmovilización, atrapamiento.

\section{Introducción}

Las enzimas son catalizadores biológicos, de naturaleza proteica, altamente específicos. Su origen biológico es responsable de algunas de sus ventajas y limitaciones con respecto a los catalizadores químicos. Dos de las características que han limitado la aplicación de las enzimas en diversos procesos son: las condiciones de trabajo bajo las cuales son estables y su solubilidad en agua, esto último las hace difíciles de separar del medio para reutilizarlas. Con los métodos de inmovilización los problemas anteriores se han solventado en gran medida (Voet y Voet, 2006).

La inmovilización enzimática se puede definir como el confinamiento de la enzima en un soporte, lo cual limita su movimiento, pero conserva su poder catalítico. La inmovilización además aumenta la estabilidad de la enzima y hace posible su reutilización al mantenerla en forma insoluble. No obstante, la inmovilización también presenta algunos inconvenientes como la alteración de la conformación de la enzima, pérdida de actividad, heterogeneidad en el sistema soporte-enzima (ya que habrá enzimas unidas al soporte en mayor o menor grado), y el incremento en el costo de la enzima inmovilizada (Arroyo, 1998).

Existen diversos métodos para inmovilizar enzimas, los cuales se pueden dividir en dos categorías de acuerdo al tipo de unión que ocurre entre el soporte y la enzima: unión física y unión química. Dentro del primer grupo encontramos dos variantes: atrapamiento e inclusión en membranas, y entre los métodos que se basan en una unión química están la unión a soportes y el reticulado (Lupo y González, 2012). En la presente práctica empleamos un método de atrapamiento para inmovilizar la enzima pectinasa en un gel de alginato.

\footnotetext{
a Alumno de la Licenciatura en Química en Alimentos.

${ }^{\mathrm{b}}$ Profesor Investigador del Área Académica de Química

* Autor de correspondencia.

Correos electrónicos: avilescabralalimentos@gmail.com, javierdj03@gmail.com, airen-e250@ hotmail.com, luchouaeh@gmail.com, icelabeltran@gmail.com
}

\section{Materiales y métodos}

\subsection{Preparación de soluciones}

Se prepararon $25 \mathrm{ml}$ de alginato de sodio al $2 \%$, para lo cual se pesaron $0.5 \mathrm{~g}$ de alginato de sodio, se disolvieron en un poco de agua caliente y se aforó el volumen a $25 \mathrm{ml}$, usando también agua caliente (aproximadamente a $40^{\circ} \mathrm{C}$ ). Para preparar la solución enzimática se pesaron $0.25 \mathrm{~g}$ de pectinasa (Sigma-Aldrich No. E.C. 3.2.1.15) que se disolvieron en aproximadamente $5 \mathrm{ml}$ de agua y finalmente se aforaron a 25 ml. Finalmente, se preparó una solución de cloruro de calcio $0.3 \mathrm{M}$, para lo cual se pesaron $2.5 \mathrm{~g}$ de cloruro de calcio, se disolvieron en aproximadamente $50 \mathrm{ml}$ de agua y después se aforaron a $250 \mathrm{ml}$.

\subsection{Inmovilización de pectinasa}

Se mezclaron las soluciones de pectinasa y la de alginato de sodio y se vaciaron en una bureta de $50 \mathrm{ml}$, debajo de la cual se colocó un vaso de precipitado en el que se vertió previamente la solución de cloruro de calcio (Figura 1). Esta última solución se mantuvo en agitación constante (menor a $150 \mathrm{rpm})$. Se revisó que la punta de bureta quedará aproximadamente a $1 \mathrm{~cm}$ de la solución de cloruro de calcio y entonces se abrió la llave de la bureta de manera que goteara para que al caer las gotas se formaran las esferas de alginato que contenían la enzima. Una vez que goteó todo el contenido de la bureta, se filtraron las esferas, usando un embudo y papel filtro, se colocaron en un frasco de vidrio con tapa, se les adicionó agua destilada hasta cubrirlas y se guardaron en refrigeración para su posterior uso. 
Los reactivos, materiales y equipos empleados en la práctica se enlistan a continuación:

$0.5 \mathrm{~g}$ Alginato de sodio

0.25 g Pectinasa de Aspergillus niger (Sigma-Aldrich No. E.C. 3.2.1.15)

2.5 g Cloruro de calcio

1 Papel filtro de $20 \times 20 \mathrm{~cm}$ aproximadamente

1 Soporte universal

1 Bureta de $50 \mathrm{ml}$

1 Pinzas para bureta

1 Pipeta de $10 \mathrm{ml}$

3 Matraz aforado de $25 \mathrm{ml}$

3 Vasos de precipitado de $25 \mathrm{ml}$

1 Vaso de precipitado de $100 \mathrm{ml}$

1 Frasco de vidrio de $250 \mathrm{ml}$ con tapa

1 Embudo de vidrio de tallo corto de $15 \mathrm{~cm}$ de diámetro

1 Parrilla con agitación

1 Potenciómetro

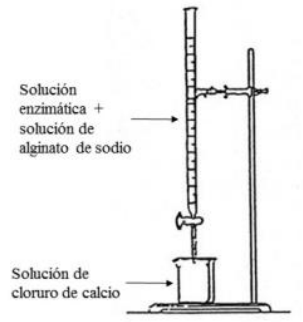

Figura 1: Disposición de la bureta para la formación de las esferas Fuente: Modificada de: http://2.bp.blogspot.com/r8DYk7O9yhU/Vk7mAWcT7yI/AAAAAAAAts4/j8164qrXjtY/s320/bure ta.jpg

\section{Resultados y discusión}

En la Figura 2 se muestran las esferas de alginato obtenidas, en cuyo interior se encuentra la pectinasa inmovilizada. El proceso de inmovilización fue rápido y sencillo, una vez que las gotas de alginato de sodio caen en la solución de cloruro de calcio hay un intercambio de iones: sodio por calcio, lo cual permite que se forme alginato de calcio que gelifica, y en cuya red quedan atrapadas las enzimas.

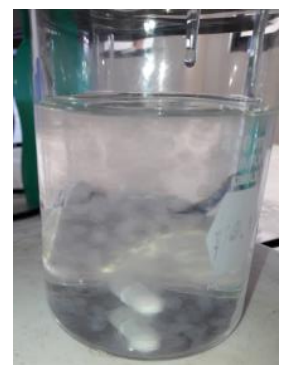

Figura 2: Formación de esferas de alginato de sodio con la enzima.

Con la realización de la práctica fue posible comprobar el mecanismo de gelificación del alginato en presencia de iones multivalentes, en este caso fue el ion fue el calcio. El alginato es un polisacárido lineal formado por dos monómeros: el ácido $\alpha$-L-gulurónico $(\mathrm{G})$ y el ácido $\beta$-Dmanurónico (M) que se pueden distribuir en secciones formando homopolímeros tipo bloques G (-GGG-), bloques M
(-MMM-) o heteropolímeros con bloques $\mathrm{G}$ y $\mathrm{M}$ alternados La flexibilidad o rigidez del gel formado van a depender en gran medida del contenido de $\mathrm{G}$, de la distribución de los monómeros, así como de la carga y volumen que los grupos carboxílicos le confieren. En el proceso que se ensayó en la práctica, la gelificación ocurrió cuando un bloque $\mathrm{G}$ del alginato se enlazó a través del calcio a otro bloque $\mathrm{G}$ de la molécula, tal como lo describen Lupo y González (2012).

El factor que limitó el rendimiento del proceso fue la temperatura de la mezcla alginato-enzima, debido a que va disminuyendo paulatinamente y esto ocasiona que parte de la mezcla quede adherida a las paredes de la bureta.

De acuerdo con la literatura, el método de atrapamiento en gel de alginato no ocasiona cambios en la conformación de la enzima inmovilizada (Arroyo, 1998) y la matriz de gel permite la difusión de sustancias a través de él (Malajovich, 2017). Lo anteior se podrá comprobar en una futura práctica.

\section{Conclusiones y perspectivas}

Se comprobó la rapidez y sencillez del método de inmovilización por atrapamiento de pectinasa en gel de alginato. También se identificó como factor limitante del rendimiento del proceso a la temperatura de la mezcla alginato-enzima en la bureta. En una próxima práctica se podrán evaluar diferentes aspectos de la enzima inmovilizada para determinar lo recomendable o no del método ensayado para la inmovilización de la pectinasa.

\section{English Summary}

\section{Enzyme immobilization}

\section{Abstract}

There is a wide variety of methods to immobilize enzymes. In selecting one of them is crucial consider the enzyme in question, characteristics of the process and resources and infrastructure available. In this work, we tested the entrapment method using alginate gel to immobilize pectinase, a very useful enzyme in the food industry.

Keywords: pectinase, alginate, gelation, immobilization, entrapment.

\section{Agradecimientos}

Los autores agradecen el apoyo técnico brindado por la TLC Ernestina Viggiano Vargas para la realización del presente trabajo.

\section{Referencias}

Arroyo, M. (1998). Inmovilización de enzimas. Fundamentos, métodos y aplicaciones. Ars. Phamaceutical, 39(2), 23-39

Lupo, P. B., González, A. C. (2012). Microencapsulación con alginato en alimentos. Técnicas y aplicaciones. Revista Venezolana de Ciencia y Tecnología de Alimentos., 131-151.

Malajovich, M. A. (2 de mayo de 2017). Biotecnología Enseñanza y Divulgación. Obtenido 